\title{
Does temperature matter for COVID-19 transmissibility? Evidence across Pakistani provinces
}

\author{
Muhammad Irfan ${ }^{1,2}$ (D) $\cdot$ Muhammad $\operatorname{Ikram}^{3}$ (D) $\cdot$ Munir Ahmad $^{4}$ (D) $\cdot$ Haitao Wu $^{1,2}$ (D) $\cdot$ Yu Hao $^{1,2,5,6,7}$
}

Received: 13 March 2021 / Accepted: 9 June 2021 / Published online: 18 June 2021

(C) The Author(s), under exclusive licence to Springer-Verlag GmbH Germany, part of Springer Nature 2021

\begin{abstract}
The outbreak of novel coronavirus (COVID-19) has become a global concern that is deteriorating environmental quality and damaging human health. Though some researchers have investigated the linkage between temperature and COVID-19 transmissibility across different geographical locations and over time, yet these studies are scarce. This study aims to bridge this gap using daily temperature and COVID-19 cases (transmissibility) by employing grey incidence analysis (GIA) models (i.e., Deng's grey incidence analysis (DGIA), the absolute degree GIA (ADGIA), the second synthetic degree GIA (SSDGIA), the conservative (maximin) model) and correlation analysis. Data on temperature are accessed from the NASA database, while the data on COVID-19 cases are collected from the official website of the government of Pakistan. Empirical results reveal the existence of linkages between temperature and COVID-19 in all Pakistani provinces. These linkages vary from a relatively stronger to a relatively weaker linkage. Based on calculated weights, the strength of linkages is ranked across provinces as follows: Gilgit Baltistan $(0.715301)>$ Baluchistan $(0.675091)>$ Khyber Pakhtunkhwa $(0.619893)>$ Punjab $(0.619286)>$ Sindh $(0.601736)$. The disparity in the strength of linkage among provinces is explained by the discrepancy in the intensity of temperature. Besides, the diagrammatic correlation analysis shows that temperature is inversely linked to COVID-19 cases (per million persons) over time, implying that low temperatures are associated with high COVID-19 transmissibility and vice versa. This study is among the first of its kind to consider the linkages between temperature and COVID-19 transmissibility for a tropical climate country (Pakistan) using the advanced GIA models. Research findings provide an up-to-date glimpse of the outbreak and emphasize the need to raise public awareness about the devastating impacts of the COVID-19. The educational syllabus should provide information on the causes, signs, and precautions of the pandemic. Additionally, individuals should practice handwashing, social distancing, personal hygiene, mask-wearing, and the use of hand sanitizers to ensure a secure and supportive atmosphere for preventing and controlling the current pandemic.
\end{abstract}

Keywords Public health · Temperature · COVID-19 $\cdot$ Transmissibility $\cdot$ Grey incidence analysis models $\cdot$ Pakistan

\begin{tabular}{|c|c|c|c|}
\hline \multicolumn{2}{|c|}{ Responsible Editor: Lotfi Aleya } & \multirow[b]{2}{*}{2} & \multirow[b]{2}{*}{$\begin{array}{l}\text { Center for Energy and Environmental Policy Research, Beijing } \\
\text { Institute of Technology, Beijing 100081, China }\end{array}$} \\
\hline$\square$ & $\begin{array}{l}\text { Muhammad Ikram } \\
\text { mikram@szu.edu.cn }\end{array}$ & & \\
\hline \multirow[t]{4}{*}{$凶$} & $\begin{array}{l}\text { Yu Hao } \\
\text { haoyuking@bit.edu.cn }\end{array}$ & 3 & $\begin{array}{l}\text { Research Institute of Business Analytics and Supply Chain } \\
\text { Management, College of Management, Shenzhen University, } \\
\text { Shenzhen, China }\end{array}$ \\
\hline & $\begin{array}{l}\text { Muhammad Irfan } \\
\text { irfansahar@bit.edu.cn }\end{array}$ & 4 & $\begin{array}{l}\text { School of Economics, Zhejiang University, Hangzhou } 310058 \text {, } \\
\text { China }\end{array}$ \\
\hline & $\begin{array}{l}\text { Munir Ahmad } \\
\text { munirahmad@zju.edu.cn }\end{array}$ & 5 & $\begin{array}{l}\text { Beijing Key Lab of Energy Economics and Environmental } \\
\text { Management, Beijing 100081, China }\end{array}$ \\
\hline & $\begin{array}{l}\text { Haitao Wu } \\
\text { haitao.kungfuer@gmail.com }\end{array}$ & 6 & $\begin{array}{l}\text { Sustainable Development Research Institute for Economy and } \\
\text { Society of Beijing, Beijing 100081, China }\end{array}$ \\
\hline & $\begin{array}{l}\text { School of Management and Economics, Beijing Institute of } \\
\text { Technology, Beijing 100081, China }\end{array}$ & 7 & $\begin{array}{l}\text { Collaborative Innovation Center of Electric Vehicles in Beijing, } \\
\text { Beijing 100081, China }\end{array}$ \\
\hline
\end{tabular}




\section{Introduction}

In recent years, human society has experienced a variety of pandemics, i.e., the $2009 \mathrm{H} 1 \mathrm{~N} 1$ pandemic in Mexico, the 2014 polio pandemic in the Middle East, the 2014 Ebola pandemic in West Africa, and the 2016 Zika virus pandemic in Brazil (Ahmad et al. 2020a). These pandemics have resulted in a massive number of deaths and cost the global economy trillions of dollars (Razzaq et al. 2020). Another such pandemic called COVID-19 also confronted the world at the end of 2019 (Hossain et al. 2020; Iqbal et al. 2021b). The outbreak soon spread all over the world and the World Health Organization (WHO) soon declared it a global pandemic (Yasir et al. 2020; Kumar et al. 2021). There is virtually no country in the world that has not been affected by this pandemic (El-Sayed et al. 2021; Hasana et al. 2021). As of 5th June 2021, the number of confirmed COVID-19 cases reached $173 \mathrm{M}$, with $3.72 \mathrm{M}$ reported deaths (Worldometers 2020). COVID-19 has disseminated evenly in both advanced and emerging economies (Irfan et al. 2021a), and some regions are seeing an increasing trend mainly due to the unavailability of medicines and vaccines (Elavarasan et al. 2021). In addition to growing public health issues, pandemics cause devastating socioeconomic predicaments in disease-ridden areas (Ali et al. 2020).

The COVID-19 virus is a member of the coronavirus family "severe acute respiratory syndrome" (SARS) and exhibits flu-like symptoms (Fu et al. 2021). Given that weather (temperature) is an important variable in predicting flu, it is likely to be a crucial factor for the transmissibility of COVID19 as well (Sajadi et al. 2020). Since extreme cold, low, and high temperatures can lead to flu, fever, cold, pneumonia, and cough, which are the potential symptoms of COVID-19 (Iqbal et al. 2020), it becomes pivotal to understand how temperature is correlated with novel infections and COVID-19 transmissibility in Pakistan during the current pandemic.

Like other countries, Pakistan could not prevent the spread of the growing pandemic and has been striving against the novel coronavirus (Iqbal et al. 2021a). On 26th February 2020, the Ministry of Health of the government of Pakistan reported the first confirmed COVID-19 case in Karachi. Another case was confirmed in Islamabad on the same day by the Pakistan Federal Ministry of Health (Abid et al. 2020). The total number of COVID-19 cases increased to 20 within the next 15 days. All these cases were found to involve a recent history of travel from Syria, London, and Iran (Shim et al. 2020). At present, the cases are increasing at an alarming rate, and the situation is getting worst. According to official statistics, the total number of confirmed COVID-19 cases in Pakistan reached 930,511 with 21,189 deaths (GOP 2021). Punjab Province have the highest number of cases, followed by Sindh, Khyber, Pakhtunkhwa, Baluchistan, and Gilgit Baltistan, respectively (GOP 2021). Figure 1 compares the
COVID-19 cases across the all affected Pakistani provinces, while Fig. 2 compares the temperature pattern across these provinces (NASA 2021).

Several initiatives have been taken by the Pakistani government in the form of isolation centers, authorized hospitals, testing facilities, case tracing, and risk communication to prevent the spread of COVID-19 and strengthen the provinces by providing an appropriate and effective response to the possible events caused by the novel coronavirus. For instance, Pakistan's Ministry of National Health Services, Regulation \& Coordination (NHRC) declared the "National Action Plan for Preparedness \& Response to COVID-19" to consolidate the state through adequate and efficient solutions to the potential consequences of the pandemic (Sherin 2020). In addition, strict restrictions in the form of quarantine policy and social distancing policy have been imposed (Waris et al. 2020). Regardless of these efforts, the most important challenge that Pakistan is currently facing is the fight against COVID-19, which has gained the attention of the international community recently (Anser et al. 2020).

The former studies were mainly centered on the prevention and control of diseases, i.e., malaria, H1N1 flu, dengue, AIDS, Chikungunya, and Zika (Saha and Samanta 2019; Vairo et al. 2019; Hausman et al. 2020; Kaur et al. 2021; Wang et al. 2021). Among them, the first array of studies considered the epidemiology of diseases (Adams et al. 2019; Mosnier et al. 2019; Cissoko et al. 2020). The second batch of studies focused on conducting surveys to find the impact of certain factors on the prevention of epidemic (Preti et al. 2020; Wenjun et al. 2020). The third batch of studies focused on assessing disease profiles to devise their precautionary and regulatory mechanisms (Lalmuanawma et al. 2020; Matterne et al. 2020). Finally, investigating the perception of individuals about personal protective equipment (i.e., face masks, gloves, helmets, safety glasses, shoes, vests, and full body suits) to prevent epidemics like MERS-CoV, SARS-CoV, and COVID-19 was the focus of the fourth group of studies (Chughtai and Khan 2020; MacIntyre and Chughtai 2020; Ahmad et al. 2021; Irfan et al. 2021b).

Recently, some researchers have examined the nexus between temperature and COVID-19. For instance, Dalziel et al. (2018) reported that temperature has a considerable effect on virus transmission. Shahzad et al. (2020a ) scrutinized the effect of temperature on COVID-19 in the most affected Chinese provinces and revealed a positive relationship between temperature and COVID-19. The spread of infectious diseases has been related to climate change (Ghalhari and Mayvaneh 2016). Dry or cold weather conditions favored viral diseases such as influenza. Tan et al. (2005) reported that temperature has a significant relationship with the 2003 SARS$\mathrm{CoV}$ outbreak in major Chinese cities such as Guangzhou and Beijing. The temperature was considerably low during the 2003 SARS epidemic, and the possibility of an augmented day-to- 
Fig. 1 Comparison of COVID-19 cases across the affected Pakistani provinces. Data source: GOP (2021)

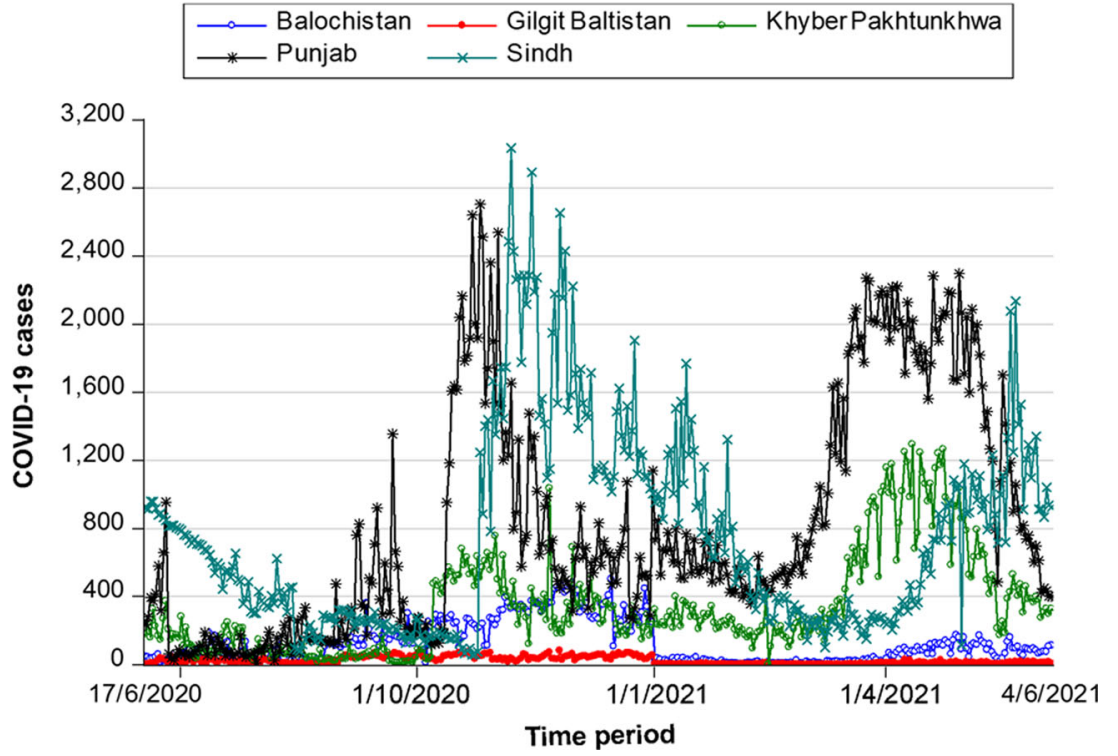

day frequency might be eighteen times greater than at high temperatures. Due to the warm season, the SARS outbreak was contained and ended in July 2003 (Liu et al. 2020). Raza et al. (2020) concluded that COVID-19 spread in countries having low average temperatures $\left(3-17^{\circ} \mathrm{C}\right)$. The Chinese scholars correlated temperature and the COVID-19 pandemic, as the dispersion of the pandemic was slower in China's warm areas (Shi et al. 2020). The temperature has a significant effect on COVID-19, as it considerably influenced the dispersion of COVID-19 in China (Qi et al. 2020).

Similarly, Sajadi et al. (2020) examined the relationship between temperature and respiratory viruses and discovered that temperature fluctuations have a significant effect on COVID-19 mortality. Prata et al. (2020) proposed that average temperature fluctuations may have a major effect on the
COVID-19. Jahangiri et al. (2020) argued that ambient temperature can be a critical factor in the transmissibility of the pandemic. Tosepu et al. (2020) investigated the relationship between the COVID-19 outbreak and temperature in Indonesia. The results indicated a strong association between COVID-19 and temperature. In Korea, the spread of influenza was linked with low temperatures (Park et al. 2020). In Turkey, Şahin (2020) investigated the relationship between temperature and COVID-19. The results confirmed the temperature-COVID-19 relationship. Bashir et al. (2020) exposed the relationship between temperature and COVID-19 in the USA. Correlation analyses established a statistically significant relationship between the two variables.

Despite the long-standing interest of earlier researchers, studies examining the relationship between temperature and
Fig. 2 Comparison of temperature pattern in the COVID-19 affected Pakistani provinces. Data source: NASA (2021)

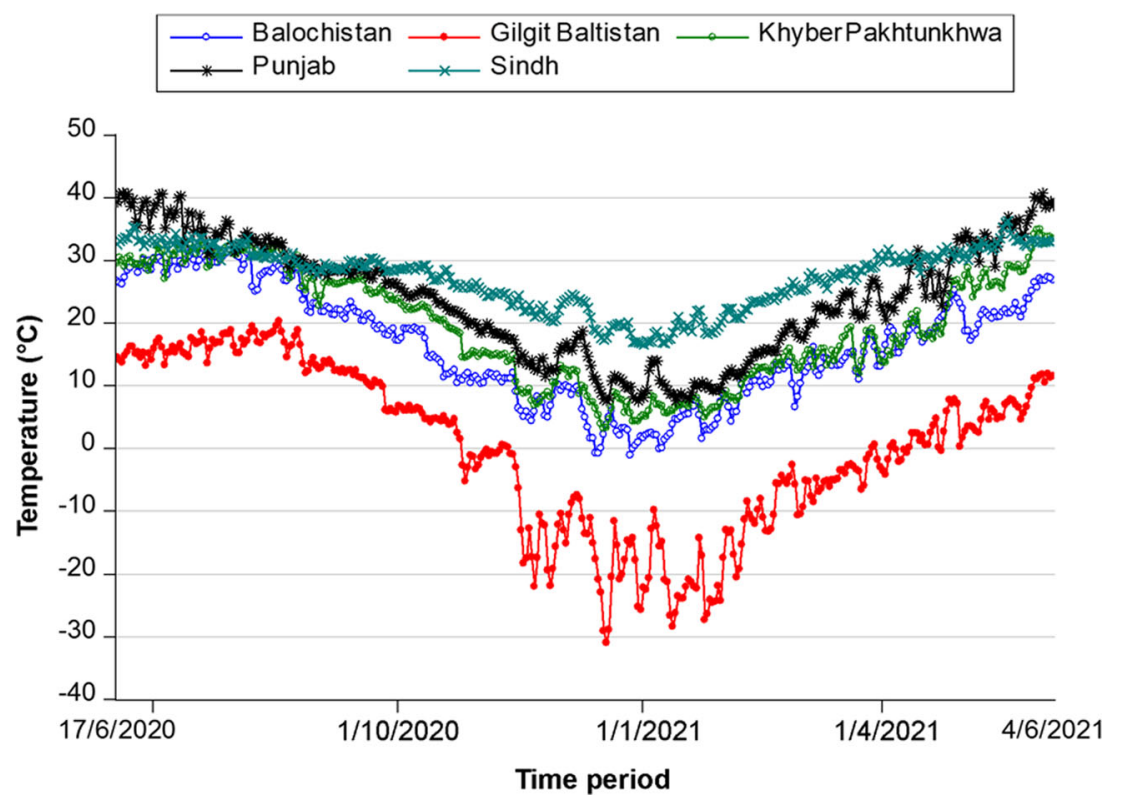


COVID-19 are scarce in tropical climate countries like Pakistan. In terms of population, Pakistan ranks 5th in the world with a huge population of $224.9 \mathrm{M}$ (Countrymeters 2021). The WHO warned that unless appropriate precautionary steps are taken, Pakistan could become the next COVID19 hotspot (Raza et al. 2020). Pakistan is a developing country (Irfan et al. 2020a, b), equipped with fewer resources and limited healthcare facilities compared to the developed economies (Hussain et al. 2021; Khan et al. 2021). Taking these realities into account, there is a dire need to conduct a comprehensive research in the Pakistani context that has a negligible impact on human lives and the environment. This study investigates the nexus between temperature and COVID-19 by considering the following research questions. (i) What are the consequences of temperature variations on COVID19 transmissibility in Pakistan? (ii) Does COVID-19 prove to be evil or a blessing in disguise for the climate?

The current study provides threefold contributions in this regard. Firstly, we apply the advanced mathematical decisionmaking models in this study to investigate the temperatureCOVID-19 transmissibility nexus among all affected provinces of Pakistan. To the best of our knowledge, this study is the first of its kind to scrutinize this nexus from the perspective of grey incidence analysis (GIA) models such as Deng's grey incidence analysis (DGIA) model, the absolute degree GIA (ADGIA) model, the second synthetic degree GIA (SSDGIA) model, and the conservative (maximin) model. These models have several benefits over traditional statistical models. For instance, they offer increased accuracy and provide accurate results even on small sample size (Ikram et al. 2021). The prior statistical models require detailed information on various dimensions (Knüppel 2014; Mazzeu et al. 2018). However, GIA models have the ability to handle increased complexity. Based on these benefits, we employ grey models for the empirical analysis. Secondly, we contribute to the existing pool of literature by investigating the linkages between temperature and COVID-19 transmissibility, prioritizing these links across all Pakistani provinces. Finally, a three-dimensional diagrammatic analysis is performed to examine the correlation between temperature and COVID-19 cases (per million persons) for each province over time. The lessons learned from this study will help governments and decision-makers to formulate better pandemic prevention and control policies.

\section{Materials and methods}

\section{Collection of data}

The NASA database was accessed to collect the daily mean temperature data (NASA 2021), while the data on COVID-19 cases were obtained from the official website of the government of Pakistan (GOP 2021). The capital city of each province was selected for temperature input, as these cities contain the majority of the population and better healthcare facilities. Hence, the flow of patients is maximum in such cities compared to other cities. In addition, the presence of an international airport in each capital city indicates high risks of virus infection. The data used in this study were taken from 17 June 2020 to 31 December 2020. Grey System Modeling Software (v 8.0) was employed to test the linkage between temperature and COVID-19 transmissibility by employing state-of-the-art mathematical decision-making models such as DGIA, ADGIA, and SSDGIA models. Microsoft Excel and MATLAB were used to design these models. In addition, the conservative (maximin) model was used to make a decision in an uncertain environment.

\section{Grey incidence analysis models}

Grey system theory got recognition in 2000. GIA models are also known as grey relational analysis (GRA) models. These models are considered primary components of modern grey system theory (Rehman et al. 2020). GIA models and the grey relational grade (GRG) concept were first proposed by Professor Deng in 1985. Since then, they have been used to deal with insecurity problems regarding inadequate information and ambiguous processes in different spheres of learning. GIA models have been applied in several areas, such as energy, medical science, management, environmental studies, and engineering studies (Ikram et al. 2020a). GIA models offer the most accurate and best solution compared to traditional and well-known statistical data analysis methods (Javed and Liu 2018a). Statistical models generally need to follow probability distribution assumptions, which can be met only for large samples. If these assumptions are violated, the findings could suffer from several statistical biases (Little and Rubin 2019). In contrast, GIA models do not require following certain probability distribution assumptions. In addition, as the main advantage of utilizing GIA models, they provide accurate results based on a small set of data (Diba and Xie 2019; Ikram et al. 2020b; Javed et al. 2020; Rehman et al. 2021; Abid et al. 2021). Wang (2017) stated that GIA models are better than system analysis statistical models. The grey incidence concept involves using the proximity degree for an open data configuration geometrical curve to determine their relationships in close proximity (Liu et al. 2017a).

First, the data on all of Pakistan's COVID-19-affected provinces were normalized and exported for analysis purposes. Second, the relationship between temperature and COVID-19 transmissibility was investigated by employing GIA models. Third, the weights from the GIA models were taken as a basis for the ranking approach. In addition, alternative decision criteria were developed. Finally, the conservative (maximin) criterion was used to realize the effect of 
temperature variations on COVID-19 transmissibility in the affected provinces of the country.

\section{Deng's grey incidence analysis model}

Considering this model's unique specification, multiple realistic problems in different domains, in the case of both empirical and theoretical questions can be handled by this method (Mahmoudi et al. 2020). The five steps included in measuring Deng's GRG of two datasets represented by $X_{0}$ and $X_{1}$ are shown below.

Step 1. The first step includes the computation of the initial image of $X_{0}$ and $X_{i}, I=1,2, \ldots, m$, where:

$$
\begin{aligned}
X^{\prime} i & =X i / X i(1)=\left(X^{\prime} i(1), X^{\prime} i(2), \ldots, X^{\prime} i(n)\right) ; i \\
& =0,1,2,3 \ldots, m
\end{aligned}
$$

Step 2. The second step estimates the sequence difference $X_{0}^{\prime}$ and $X_{i}^{\prime}, I=1,2,3, \ldots, m$, as follows:

$$
\begin{aligned}
\Delta i(l) & =\left\|X^{\prime} o(l)-X^{\prime} i(l)\right\|, \Delta \\
& =(\Delta i(1), \Delta i(2), \ldots, \Delta i(n)), i=1,2,3, \ldots, m
\end{aligned}
$$

Step 3. The third step consists of calculating the maximum and minimum differences as follows:

$\mathcal{M}=\max _{i} \max _{l} \Delta_{i}(L), m=\min _{i} \min _{l} \Delta_{i}(L)$

Step 4. The fourth step computes the grey incidence coefficients (referred to as the coefficients of the grey/ point relation), as shown in Eq. 4.

$$
\begin{aligned}
\gamma_{0 i}(l) & =\frac{m+\xi \mathcal{M}}{\Delta i(l)+\xi \mathcal{M}} ; \xi \in(0,1) ; l=1,2, \ldots, n ; i \\
& =1,2, \ldots, m
\end{aligned}
$$

Here, $\xi$ represents the distinguishing coefficient and is supposed to be $\xi=0.5$. Although there is no substantial explanation behind this assumption, analysts are still paying attention to investigating it (Javed and Liu 2018b).

Step 5. The final step calculates the GRG, which is given by the following equation.

$\gamma_{0 i}=\frac{1}{n} \sum_{l=1}^{n}\left(\gamma_{0 i}(L)\right) ; i=1,2, \ldots, m$

When this fractional shape of $1 / n$ is modified by weights $w_{k}$, it can be written as follows:

$\gamma_{0 i}=\sum L=1 n\left(\gamma_{0 i}(L) \times w l\right) ; i=1,2,3 \ldots, m$

Sarikaya and Güllü (2015) reported that if the effect on the mechanism is inconsistent for every factor, then the weights' sum will be equal to one, for example, $\sum w l=1$. Generally, $\frac{1}{n}$ suggests that the weighting parameters are distributed uniformly, while $w_{k}$ implies that the weighting criteria are unequally distributed, which is normal for real-life problems. Thus, the debate under discussion specifies that the GIA model's first half could be associated since every free factor is uniformly weighted in all affected provinces of the country.

\section{Absolute degree grey incidence analysis model}

The DGIA model offers an understanding of the mutual effects among factors (as shown in the grey dataset arrangement), whereas the ADGIA model provides direct insights into the interactions among these variables (Zhicai and $\mathrm{Li}$ 2018). In both scenarios, the main goal of these models is to fulfill the primary purpose of examining the geometric vicinity of succession curves by obtaining a significant value in research. In two identical intervals between $X_{0}$ and $X_{1}$, the following steps are taken to evaluate the absolute grey incidence:

Step 1. Based on the interval series in $X_{0}$ and $X_{1}$, the zero starting points $\left(X_{0}^{0}\right.$ and $\left.X_{1}^{0}\right)$ are computed during the first step.

Step 2. The second step consists of calculating $\left|s_{0}\right|,\left|s_{1}\right|$ and $\left|s_{1}-s_{0}\right|$.

Step 3. Finally, the last step calculates the absolute degree of grey incidence $\left(\varepsilon_{01}\right)$ over time interval series, i.e., $X_{0}$ and $X_{1}$, as shown below.

$\varepsilon_{01}=\frac{1+\left|s_{0}\right|+\left|s_{1}\right|}{1+\left|s_{0}\right|+\left|s_{1}\right|+\left|s_{1}-s_{0}\right|}$. 
Definition 1 Deng's degree of grey relational grade (DGRG)

Deng's GIA model suggests DGRG, as shown by the following equation.

$\gamma_{0 i}=\sum_{l=1}^{n}\left(\gamma_{0 i}(L) \times w_{l}\right) ; i=1,2,3, \ldots, m$,

or

$\gamma_{0 i}=\frac{1}{n} \sum_{l=1}^{n}\left(\gamma_{0 i}(L)\right) ; i=1,2,3, \ldots, m$,

Here, $\gamma_{0 i}(L)$ indicates the grey relational coefficient. The weighted formula is indicated by the DGIA model's first equation, and the non-weighted formula is indicated by the second equation.

Definition 2 Absolute degree grey relational grade (ADGRG) The ADGIA model provides the ADGRG (see Eq. 7).

\section{Definition 3 Zero-scale point image}

Suppose that the system behavior data series is shown as $X_{i}=\left(x_{i}(1), x_{i}(2), \ldots ., x_{i}(n)\right)$ and $X_{i}(L) c=\left(x_{i}(L) c-x_{i}(1)\right) ; L=1$, $2,3, \ldots n$. Here, $C$ is a point operator beginning at zero, and $X_{i} c$ is the null-scale representation of $X_{i} . X_{i} c$ is represented by the following equation.

$X_{i} C=X_{1}^{0}=\left(X_{i}^{0}(1), X_{i}^{0}(2), \ldots . . X_{i}^{0}(n)\right)$

We assume that $X_{i}$ and $X_{j}$ contain similar durations of one time-interval series factor (Liu et al. 2017b) and are represented as follows:

$X_{i}^{0}=\left(X_{i}^{0}(1), X_{i}^{0}(2), X_{i}^{0}(3) \ldots, X_{i}^{0}(n)\right)$

$X_{j}^{0}=\left(X_{j}^{0}(1), X_{j}^{0}(2), X_{j}^{0}(3) \ldots, X_{j}^{0}(n)\right)$

Thus,

$$
\begin{aligned}
& \left|s_{i}\right|=\left|\sum_{l=2}^{n-1} X_{i}^{0}(L)+\frac{1}{2} X_{i}^{0}(n)\right| \\
& \left|s_{j}\right|=\left|\sum_{l=2}^{n-1} X_{j}^{0}(L)+\frac{1}{2} X_{j}^{0}(n)\right|
\end{aligned}
$$

The absolute difference between $s_{i}-s_{j}$ is calculated as follows:

$$
\left|s_{i}-s_{j}\right|=\left|\sum_{l=2}^{n-1}\left(X_{i}^{0}(L)-X_{j}^{0}(L)\right)+\frac{1}{2}\left(X_{i}^{0}(n)-X_{j}^{0}(n)\right)\right|
$$

\section{Second synthetic degree grey incidence analysis model}

Javed and Liu (2018b) proposed the SSDGIA model, which provides the second synthetic degree grey relational grade (SSDGRG) (see Eq. 16). $\rho_{i j}=\theta \varepsilon_{i j}+(1-\theta) \gamma_{i j} ; \theta \in[0,1]$

Here, $i j$ denotes the SSDGRG, $\varepsilon_{i j}$ denotes the ADGRG, and $\gamma_{i j}$ denotes the DGRG. At some points, the DGIA model depends on the coefficient of grey incidence/relation. According to the literature (Javed and Liu 2019; Liu et al. 2017a), $\varepsilon$ measures the correlation (integral proximity), and $\gamma_{i j}$ is used to measure grey influence (partial proximity). A high value means a high correlation and a strong influence and vice versa. ij is used to analyze the overall impact (correlation and influence) of temperature on the number of COVID-19 cases in Pakistan. A high value of ${ }_{i j}$ implies a strong correlation and influence between the variables and vice versa. Likewise, the ADGIA model at some points depends on an integrated (larger) viewpoint (Liu et al. 2017b). The SSDGIA model determines the overall association between two sequence stages and an integral function. Javed and Liu (2019) suggested that the first synthetic degree GIA model is implemented in combination with DGIA and ADGIA. Figure 3 presents the research framework of this study.

The SSDGIA model was developed based on the operating norms of the SDGIA model. When deciding on a detailed placement, it is suggested to consider $\theta=0.5$, which also incorporates the values of $\gamma$ and $\varepsilon$ without favoring one over the other, and if possible, $\theta$ may be modified. If somebody wishes to favor $\gamma$, then at that stage, the $\theta$ value could be reduced, but if somebody wishes to favor $\varepsilon$, then at that point, the $\theta$ value could be increased.

\section{Results and discussions}

The data analysis of COVID-19-affected Pakistani provinces is shown in Table 1. The association between the grey incidence data sequence and the degree of GIA models must not be zero, and their negligible values may change (Liu et al. 2017a). For the ADGIA model, there is a strong relationship between temperature and COVID-19 transmissibility in Gilgit Baltistan due to a maximum weight score ADGRG $(\varepsilon)$ of 0.808635, whereas Baluchistan and Khyber Pakhtunkhwa ranked 2nd and 3rd by securing weight scores ADGRG $(\varepsilon)$ of 0.562743 and 0.520832 , respectively, indicating that when the temperature is low, COVID-19 cases increase. On the other hand, Punjab and Sindh have the least influential association between temperature and COVID-19 transmissibility by securing weight scores ADGRG $(\varepsilon)$ of 0.510426 and 0.503054 , respectively. This is attributed to the fact that both these provinces have high temperatures compared to other provinces (Irfan et al. 2019a, b). Based on the ADGIA model, there is a strong correlation between temperature and the number of COVID-19 cases in Pakistan. These results are 
Fig. 3 Research framework utilized in this study. Notes: DGIA, Deng's grey incidence analysis; ADGIA, absolute degree grey incidence analysis; SSDGIA, second synthetic degree grey incidence analysis; SSDGRG, second synthetic degree grey relational grade

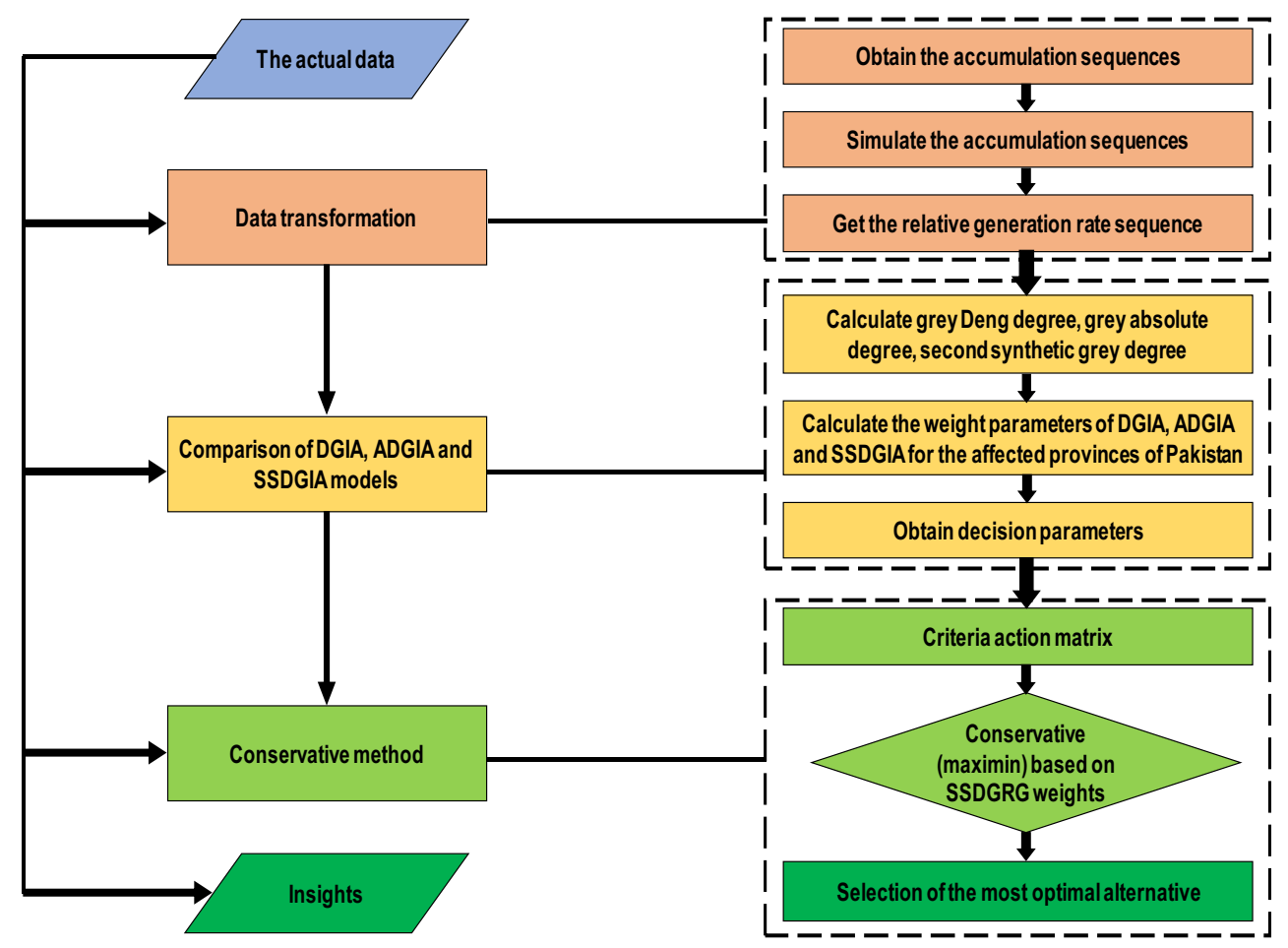

supported by the study of Qi et al. (2020), as they reported that COVID-19 transmission is associated with temperature in China.

Similarly, in the case of DGIA, Baluchistan shows the strongest association between temperature and COVID-19 transmissibility by obtaining the highest weight score DGRG $\left(\gamma_{i j}\right)$ of 0.787438 , followed by Punjab at 0.729361 . These findings are consistent with the study results of Tosepu et al. (2020), as they found that temperature was significantly correlated with the COVID-19 pandemic. In the cases of Sindh and Gilgit Baltistan, a weak relationship was found, as they obtained weight scores DGRG $\left(\gamma_{i j}\right)$ of 0.700418 and 0.621965, respectively. Khyber Pakhtunkhwa obtains a weight score DGRG $\left(\gamma_{i j}\right)$ of 0.717741 and exhibits the same ranking based on ADGIA and DGIA models. According to the DGIA model, variations in temperature have a strong influence on COVID-19 transmissibility, which implies that lower temperatures cause a high number of COVID-19 cases. A study performed by Iqbal et al. (2020) observed a strong influence of increased temperature on slowing down COVID19 cases in Wuhan, China. In comparison, the SSDGIA model shows that the association between temperature and COVID19 transmissibility is the strongest in Gilgit Baltistan, which obtains the maximum weight score SSDGRG $\left(\rho_{i j}\right)$ (0.715301). Based on the calculated weights, the strength of the linkages between the two variables is as follows: Gilgit Baltistan $(0.715301)>$ Baluchistan (0.675091) > Khyber Pakhtunkhwa (0.619893) > Punjab (0.619286) > Sindh (0.601736). The variation in the strength of linkage between provinces is attributed to the differences in temperature intensity.

A ranking criterion for the selected provinces was established based on the data analyzed by the SSDGIA model (see Table 2). Since the SSDGIA model is the average
Table 1 Grey incidence analysis models' evaluation of affected Pakistani provinces for temperature and COVID-19 transmissibility

\begin{tabular}{lllllll}
\hline Provinces & ADGIA & Rank & DGIA & Rank & SSDGIA & Rank \\
\hline Punjab & 0.510426 & 4th & 0.729361 & 2nd & 0.619286 & 4th \\
Sindh & 0.503054 & 5 th & 0.700418 & 4th & 0.601736 & 5th \\
Khyber Pakhtunkhwa & 0.520832 & 3rd & 0.717741 & 3rd & 0.619893 & 3rd \\
Baluchistan & 0.562743 & 2nd & 0.787438 & 1 st & 0.675091 & 2nd \\
Gilgit Baltistan & 0.808635 & 1st & 0.621965 & 5 th & 0.715301 & 1st \\
\hline
\end{tabular}

Notes: ADGIA, absolute degree grey incidence analysis; DGIA, Deng's grey incidence analysis; SSDGIA, second synthetic degree grey incidence analysis. The models ADGIA, DGIA, and SSDGIA calculated weights, namely, $\operatorname{ADGRG}(\varepsilon)$, DGRG $\left(\gamma_{i j}\right)$, and SSDGRG $\left(\rho_{i j}\right)$, respectively 
Table 2 Province wise ranking criteria of COVID-19 cases in Pakistan based on grey incidence analysis models

\begin{tabular}{lcc}
\hline Provinces & Grey incidence analysis (GIA) models & Ranking description \\
\hline $\begin{array}{l}\text { Province wise COVID-19 cases in Pakistan with } \\
\text { respect to temperature }\end{array}$ & $\begin{array}{c}\text { Absolute degree grey incidence analysis } \\
\text { (ADGIA) }\end{array}$ & $\begin{array}{c}\text { Gilgit Baltistan }>\text { Baluchistan }>\text { Khyber } \\
\text { Pakhtunkhwa }>\text { Punjab }>\text { Sindh } \\
\text { Deng's grey incidence analysis (DGIA) } \\
\text { Baluchistan }>\text { Punjab }>\text { Khyber Pakhtunkhwa }> \\
\text { Sindh }>\text { Gilgit Baltistan }\end{array}$ \\
& $\begin{array}{c}\text { Second synthetic degree grey incidence } \\
\text { analysis (SSDGIA) }\end{array}$ & $\begin{array}{c}\text { Gilgit Baltistan }>\text { Baluchistan }>\text { Khyber } \\
\text { Pakhtunkhwa }>\text { Punjab }>\text { Sindh }\end{array}$ \\
& &
\end{tabular}

proximity of the ADGIA and DGIA models, the discussion of the results below is based on the SSDGIA model. It is obvious from Table 2 that Gilgit Baltistan exhibited the strongest linkage between temperature and COVID-19 transmissibility, followed by Baluchistan, Khyber Pakhtunkhwa, and Punjab, whereas Sindh Province showed the weakest linkage. The reason for this relationship is that the temperature is mostly low in Gilgit Baltistan and Baluchistan Provinces. On the other hand, in Punjab and Sindh Provinces, the temperature is considerably high. These results are in accordance with $\mathrm{Ma}$ et al. (2020), as they found a rapid spread of COVID-19 in low-temperature regions, whereas regions with high temperatures had fewer COVID-19 cases. Shi et al. (2020) conducted a study in the Chinese perspective to examine the influence of temperature on the dynamics of the COVID-19 pandemic. The study results revealed that temperatures above $8-10{ }^{\circ} \mathrm{C}$ were associated with fewer COVID-19 cases.

Interestingly, Punjab and Sindh Provinces (hightemperature regions) have more COVID-19 cases than Gilgit Baltistan, Baluchistan, and Khyber Pakhtunkhwa (low-temperature regions). Previous studies attributed this scenario to the high population density (Yin et al. 2021). In the present case, Punjab and Sindh Provinces are also densely populated. Bhadra et al. (2020) and Coşkun et al. (2021) found a positive connection between population density and COVID-19 cases. Except for this situation, the empirical findings of the present research confirmed a stronger connection between temperature and COVID-19 transmissibility in low-temperature regions (provinces) and vice versa. Bu et al. (2020) opined that temperature ranging from 13 to $19^{\circ} \mathrm{C}$ is optimal for the survival and spread of novel coronavirus. Shahzad et al. (2020b) while exploring the relationship between temperature and COVID-19 cases in the top-four regions of Spain concluded that an elevated temperature lowers the transmissibility of COVID-19 by $0.39 \%$. They further revealed that a $1{ }^{\circ} \mathrm{C}$ increase in temperature reduces the transmissibility of COVID-19 by 1 to 2 cases. Table 3 provides the SSDGIA action matrix, presenting the "second synthetic grey relations" between decision actions and decision criteria. The schematic grey relational assessment of COVID-19 transmissibility in Pakistan is presented in Fig. 4.
For robustness check, a conservative (maximum) method was adapted from Prasad (2015). This method calculates the optimal weight based on the following expression:

$$
\max L_{i}\left\{\min L_{k} v\left(L_{p}, C_{k}\right)\right\}=\max L_{p}\left\{\begin{array}{l}
0.601736 \\
0.619286 \\
0.619893 \\
0.675091 \\
0.715301
\end{array}\right\}=0.715301
$$

The optimal weight $(0.715301)$ calculated by the conservative (maximum) method is consistent with the weight calculated by the SSDGIA model in the case of Gilgit Baltistan (low-temperature region). This result means that the strongest relationship between temperature and COVID-19 transmissibility in the low-temperature region is revealed to be a robust finding. Our findings indirectly imply that due to the low temperature, Gilgit Baltistan exhibits the strongest connection between temperature and COVID-19 transmissibility. These empirical results are supported by previous research findings, as Shahzad et al. (2020a) observed a strong link between low temperatures and COVID-19 daily death counts in Wuhan, China. They further argued that temperature fluctuations had a significant impact on morbidity and mortality rates. Sudden temperature variations can lead to a burden on the heart and respiratory system, causing cardiopulmonary events (Sharafkhani et al. 2019). Pramanik et al. (2020) revealed that temperature seasonality significantly impacted COVID-19 transmission in Russia. Likewise, Chen et al. (2020a) reported that the dispersion of COVID-19 was fast in cold regions of China. Pramanik et al. (2020) discovered that temperature positively contributed to COVID-19 cases across various geographical locations around the world.

As a further argument, past studies have shown that the mortality rate of respiratory diseases increases at low temperatures (Dadbakhsh et al. 2017). Another analysis revealed that both cold and hot effects could adversely influence respiratory mortality (Li et al. 2019). Sharafkhani et al. (2019) conducted a study in Iran and found that the relative risk of respiratory and cardiovascular mortality increased during the cold season. Hansel et al. (2016) noticed that low temperatures are linked to a decline in lung function. Paull et al. (2017) conducted a study to 
Table 3 The criteria action matrix based on second synthetic degree grey incidence analysis model

\begin{tabular}{llllll}
\hline $\begin{array}{l}\text { Second synthetic degree grey incidence } \\
\text { analysis (SSDGIA) }\end{array}$ & $\mathrm{P}_{1}$ & $\mathrm{P}_{2}$ & $\mathrm{P}_{3}$ & $\mathrm{P}_{4}$ & $\mathrm{P}_{5}$ \\
\hline $\begin{array}{l}\text { Grey evaluation based on second synthetic } \\
\text { degree grey incidence analysis (SSDGIA) } \\
\text { model }\end{array}$ & 0.619286 & 0.601736 & 0.619893 & 0.675091 & 0.715301 \\
\hline
\end{tabular}

Notes: The weight score second synthetic degree grey relational grade (SSDGRG) ${ }_{\text {ij }}$ is calculated by the second synthetic degree grey incidence analysis (SSDGIA) model examine the association between cold exposure and immune function and discovered that immune function could be suppressed at low temperatures. Luo et al. (2017) indicated that under cold stress, the phagocytic role of pulmonary alveolar macrophages decreased to a great extent. Couto et al. (2018) reported that breathing in cold air causes bronchial shrinkage, which can increase the susceptibility to pulmonary infection. SARS-CoV-2 is heat sensitive, and it is difficult for it to survive in high-temperature conditions (Araújo and Naimi 2020). Ma et al. (2020) reported that "although the outdoor and indoor air environment might be similar due to the air conditioner off using and window opening for $24 \mathrm{~h}$ in the hospital patient wards during COVID-19 therapy in Wuhan"; however, their study findings disclosed that temperature affects the mortality of COVID-19 in the city. Additionally, from the broad policy perspective, it has been argued that healthcare expenditures are likely to increase environmental degradation, escalating the temperature levels (Ahmad et al. 2020b), which could reduce the COVID19 transmissibility.

As a next step, we performed a diagrammatic analysis between temperature and COVID-19 cases (per million persons). For each province under analysis, a three-dimensional

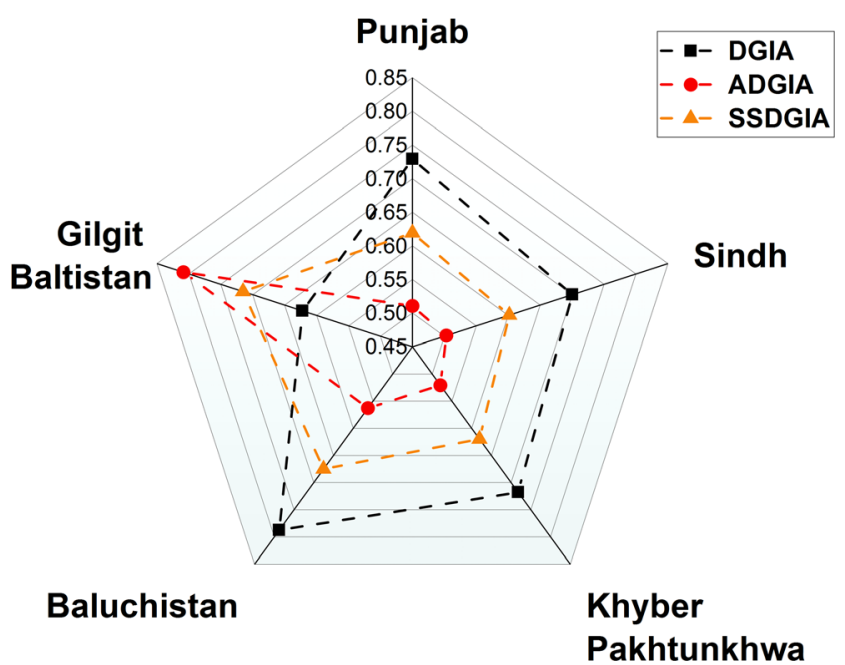

Fig. 4 Grey relational assessment of COVID-19 transmissibility in Pakistan based on GIA models. Notes: DGIA, Deng's grey incidence analysis; ADGIA, absolute degree grey incidence analysis; SSDGIA, second synthetic degree grey incidence analysis. The models DGIA, ADGIA, and SSDGIA calculated weights, namely, DGRG $\left(\gamma_{i j}\right)$, $\operatorname{ADGRG}(\varepsilon)$, and SSDGRG $\left(\rho_{i j}\right)$, respectively correlation graph involving temperature, COVID-19 cases (per million persons), and the daily time-frequency is presented (see Fig. 5). COVID-19 cases are measured per million persons to control for the influence of the population factor. Thus, the presented diagrammatic analysis allows us to observe the correlation between temperature and COVID-19 cases in the provinces studied over time. The correlation shows that more COVID-19 cases per million persons are associated with low temperatures, while fewer cases are linked to high temperatures in each province over time.

In summary, the linkages between temperature and COVID-19 transmissibility are calculated in the form of weights. The degree of weights provides the strength of association between the two variables and varies across the five provinces. The highest magnitude is found in a lowtemperature province (Gilgit Baltistan), while the lowest magnitude is revealed in a high-temperature province (Sindh). These findings are supported by the study results of Shi et al. (2020), as they found a significant relationship between temperature and COVID-19 in the low-temperature regions of China. Furthermore, the ranking of provinces based on their weights is as follows: Gilgit Baltistan $>$ Baluchistan $>$ Khyber Pakhtunkhwa $>$ Punjab $>$ Sindh. Based on this ranking, we indirectly imply that since Gilgit Baltistan is a lowtemperature province, it has the strongest connection between temperature and COVID-19 transmissibility. In contrast, Sindh is a high-temperature province, and therefore, it demonstrates the weakest linkage between the two variables. Thus, the findings indirectly support the argument that low temperatures are associated with high COVID-19 transmissibility and vice versa. Based on diagrammatic correlation analysis over time, more COVID-19 cases per million persons are related to low temperatures and vice versa. This result means that temperature and COVID-19 transmissibility are inversely correlated over time and across different provinces. Recently, some researchers have obtained similar results. For instance, Wang et al. (2021) reported that there exists a negative correlation between temperature and the COVID-19 transmissibility in China. Chen et al. (2020b) investigated the linkage between temperature and COVID-19 transmissibility using global data and discovered a significant negative linkage between COVID-19 transmissibility and temperature. Ran et al. (2020) employed the discontinuity regression method and 


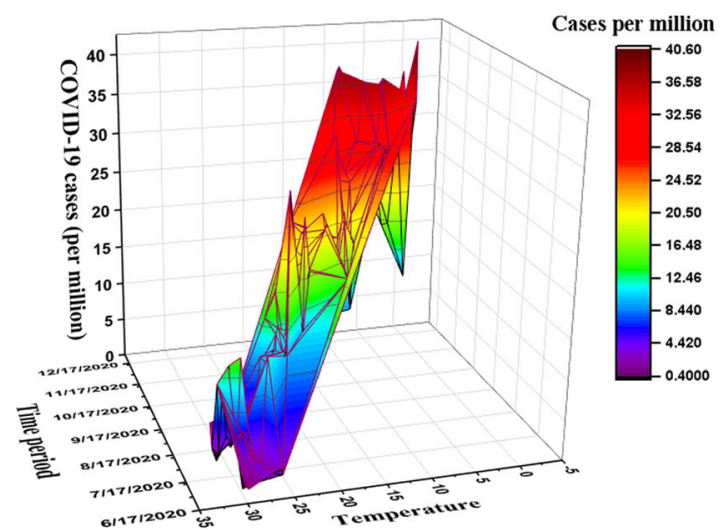

(a)

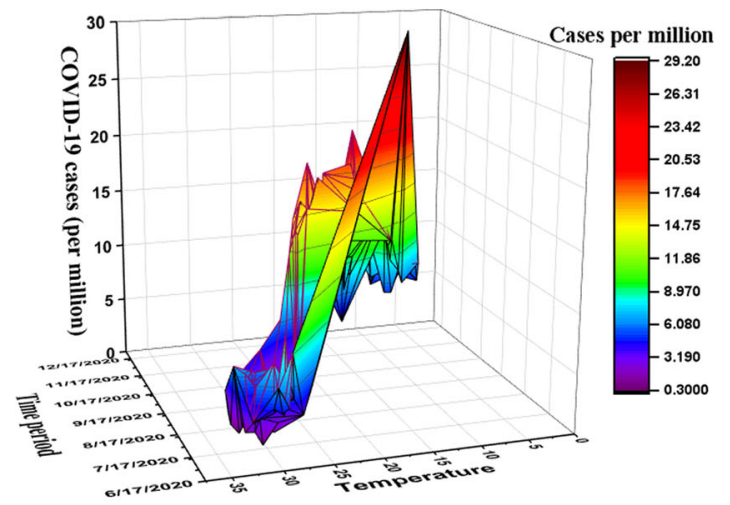

(c)

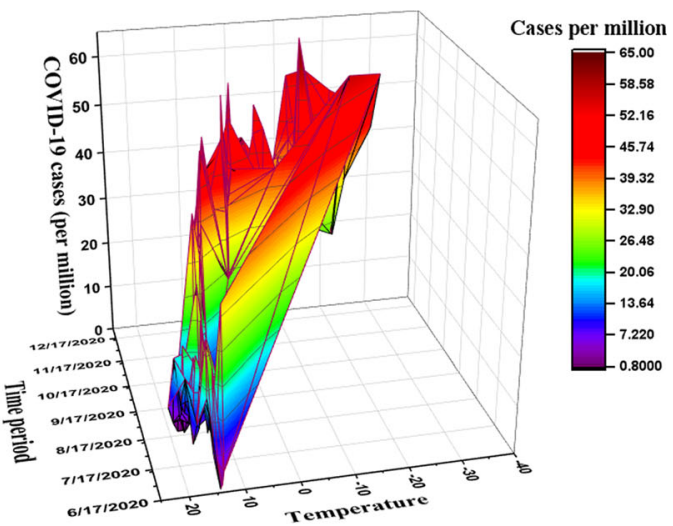

(b)

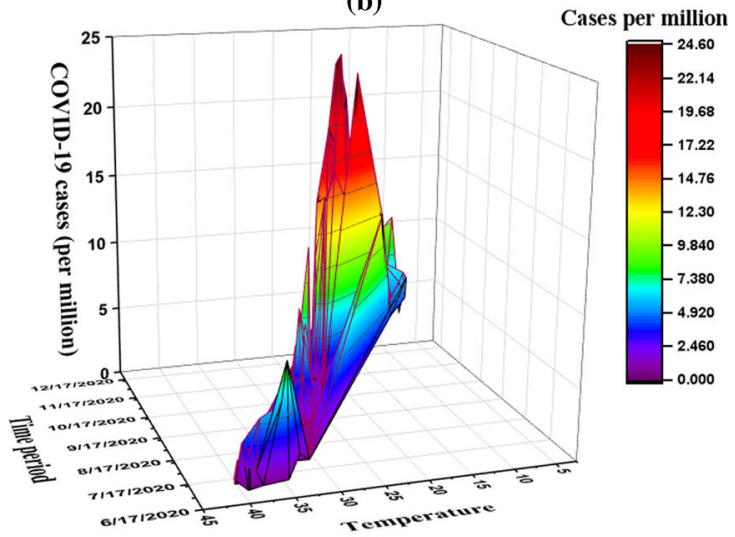

(d)

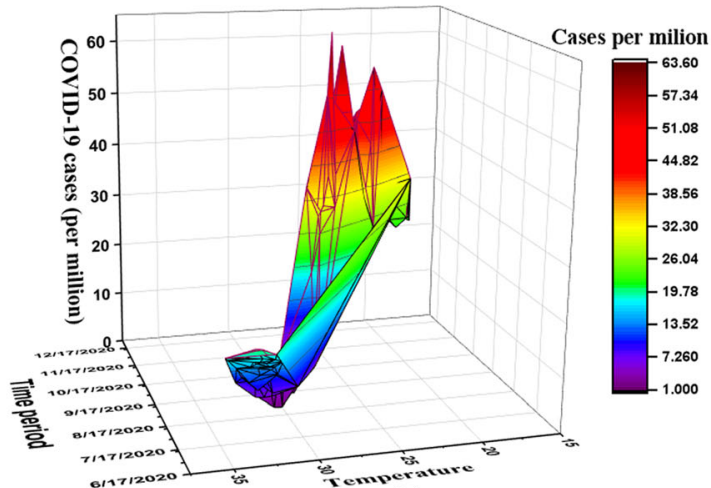

(e)

Fig. 5 A three-dimensional diagrammatic correlation between temperature and COVID-19 cases (per million persons) in Pakistani provinces. Notes: Blue color indicates fewer COVID-19 cases (per million persons) at high temperature, while red color indicates more COVID-19 cases (per million persons) at low temperature. a Baluchistan. b Gilgit Baltistan. c Khyber Pakhtunkhwa. d Punjab. e Sindh. Source: Authors' elaboration concluded that temperature has a nonlinear negative relationship with COVID-19 transmissibility.

\section{Conclusions and policy implications}

The exploration conducted in this study provides deep insights into the linkage between temperature and COVID-19 transmissibility in Pakistan's affected provinces. We comprehensively examined and discussed the relationship between temperature and COVID-19 transmissibility in a tropical climate country like Pakistan using the advanced GIA models. The research findings illustrate heterogeneous results across regions (provinces), demonstrating asymmetric behavior, as projected by GIA models. The strongest relationship between temperature and COVID-19 transmissibility was found in Gilgit Baltistan, while the weakest relationship was observed in Sindh Province. According to the weights calculated by the SSDGIA model, the rankings are as follows: Gilgit Baltistan $(0.715301)>$ Baluchistan $(0.675091)>$ Khyber Pakhtunkhwa 
$(0.619893)>$ Punjab $(0.619286)>$ Sindh $(0.601736)$. It was discovered that low-temperature provinces demonstrated strong linkages between temperature and COVID-19 transmissibility. In contrast, high-temperature provinces demonstrated weak linkages between the two variables. Based on the correlational analysis, an inverse association was found between temperature and COVID-19 cases per million persons over time.

The research findings have the following theoretical and practical implications: though research results suggest that low temperature is linked with high COVID-19 transmissibility; however, public healthcare policy governance should not wait for high temperature to beat COVID-19. The efficient implementation of social distancing policy by the Chinese government was an advancement in preventing the spread of viral infection, as the Chinese government imposed a lockdown in Wuhan City on 23 January 2020 (Tian et al. 2020). During the lockdown period, people remain at home and maintain a social distance, which eventually reduced the dispersion of COVID19 (Wang et al. 2021). The Pakistani government should take similar measures to win the fight against the pandemic. Likewise, other prevention measures, including washing hands, keeping residential and workspaces warm, using hand sanitizer, and wearing face masks, should be implemented more strictly in low-temperature regions. The pandemic impacts on our lives, societies, and economic development will be very devastating, and an unexpected rise in global unemployment is expected to skew the social and economic balance. Prospective implications include the need to create jobs and to strengthen the healthcare system in a sustainable manner. This could contribute to the creation of green jobs and provide the basis for a sustainable recovery based on new government commitments to improve climatic conditions (Irfan et al. 2020c, 2021c). Several countries, including India, Nepal, and Pakistan, have launched programs to support the government's "Green Wagers Scheme" which aims to provide financial support and green jobs through planting trees and ecosystem restoration. Additionally, the forest society can improve people's livelihoods by sustainably harvesting timber and other items under current circumstances, with a stronger focus on forestry programs. Finally, rehabilitating degraded public spaces through the construction of sustainable facilities can generate green jobs and increase ecological resilience. Low-temperature regions should be prioritized when devising pandemic mitigation strategies. Due to the increased risk of COVID-19 infection in these regions, it is important to sustain a safe and friendly atmosphere for patients in hospitals.

The limitations of the current study should not be ignored. First, there was a constraint imposed by the design, as the confounders in the association between temperature and COVID-19 transmissibility were not controlled. This is due to the fact that we have employed mathematical models in our study to scrutinize the relationship between only two variables (temperature and COVID-19 transmissibility). On the contrary, statistical models need to control the factors because they incorporate a variety of factors. Hence, future researchers may opt to use statistical models in subsequent studies to investigate the influence of other factors on COVID-19 transmissibility as well. Second, we did not focus on other meteorological factors (i.e., humidity and wind speed), which may affect COVID-19 transmissibility. Other factors such as government intervention strategies, city lockdown, school/mall closing, low public awareness about the severity of the outbreak, insufficient medical facilities, the high cost of personal protective equipment, and the failure to obtain public cooperation during the pandemic situation, including people's refusal to wear face masks, to practice social distancing, and to stay isolated from infected individuals could also influence the transmissibility of COVID-19. The present research was unable to account for these confounders for the following reasons: (i) The present research used the daily frequency data of discrete numerical variables, including temperature and COVID-19 cases. However, the above-mentioned potential confounding factors are qualitative attributes for which no data are available. Consequently, we were unable to accommodate them in any model in any form. (ii) The daily frequency data of the population density, defined as "population per unit area," was also unavailable. In the present research, we considered five Pakistani provinces for comparative analysis. In such a case, we could only find a one-time value of population density for each province; however, the underanalysis data on two variables were daily frequency-based. Thus, a single-value data of population density would be of no use in such an analysis. Hence, we were unable to consider its inclusion in the present analysis. These factors should be considered by future studies in suitable models accommodating the qualitative variables. Third, apart from these factors, social and behavioral factors should also be considered in future studies. Fourth, this study adopted an ecological time-series research approach, which may have some degree of ecological fallacy. Finally, this research revealed that temperature could influence the transmissibility ofCOVID-19 in a specific geographical area (Pakistan). The research findings need additional assessment based on other geographical regions as well.

NomenclatureSymbols $X_{o}$ and $X_{i}$, two distinct datasets; $\xi$, the unique coefficient; $\mathcal{M}$, maximum variations; $m$, minimum variations; $\gamma_{0 i}(L)$, grey coefficient of incidence; $\sum w l$, the number of weights that must be equal to one; $\frac{1}{n}$, illustration of similarly weighted criterion; $w_{b}$ unevenly distributed weighting scheme that portrays perplexing issues; $X_{0}$ and $X_{1}$, two distinct time periods; $\xi_{01}$, grey incidence in absolute terms; $X_{i}$ and $X_{j}$, zero starting points; $C$, a zero-based point operator; $X_{i} C$, zero-scale point of $X_{i} ; X_{i}^{0}$ and $X_{j}^{0}$, the variables length of $X_{i}$ and $X_{j} ; \varepsilon$, weight score of absolute degree of grey relational grade (ADGRG); $\gamma_{i j}$, weight score of Deng's grey relational grade (DGRG); $\rho_{\rangle \mid}$, weight score of second synthetic degree of grey relational grade (SSDGRG) 
Acronyms and abbreviations $A D G I A$, absolute degree grey incidence analysis; $A D G R G$, absolute degree grey relational grade; COVID-19, coronavirus disease 2019; DGIA, Deng's grey incidence analysis; $D G R G$, Deng's grey relational grade; GIA, grey incidence analysis; $G R G$, grey relational grade; $N H R C$, National Health Services, Regulation \& Coordination; SARS, severe acute respiratory syndrome; SSDGIA, second synthetic degree grey incidence analysis; SSDGRG, second synthetic degree grey relational grade

Author contribution M. Irfan: conceptualization, data curation, writing - original draft. M. Ikram: formal analysis, data handling, methodology. M. Ahmad: writing - review and editing, variable construction. $\mathrm{H}$. Wu: writing - review and editing. Y. Hao: supervision, funding acquisition, writing - review and editing.

Funding The authors acknowledge financial support from the National Natural Science Foundation of China (72073010, 71761137001, 71521002), the key research program of the Beijing Social Science Foundation (17JDYJA009), and the Joint Development Program of the Beijing Municipal Commission of Education.

Data Availability All data generated or analyzed during this study are included in this article.

\section{Declarations}

Ethics approval and consent to participate Not applicable.

Consent for publication Not applicable.

Competing interests The authors declare no competing interests.

\section{References}

Abid K, Bari YA, Younas M, Tahir Javaid S, Imran A (2020) Progress of COVID-19 epidemic in Pakistan. Asia-Pacific J Public Heal 32: 154-156. https://doi.org/10.1177/1010539520927259

Abid N, Ikram M, Wu J, Ferasso M (2021) Towards environmental sustainability: exploring the nexus among ISO 14001, governance indicators and green economy in Pakistan. Sustain Prod Consum 27: 653-666. https://doi.org/10.1016/j.spc.2021.01.024

Adams LE, Martin SW, Lindsey NP, Lehman JA, Rivera A, Kolsin J, Landry K, Staples JE, Sharp TM, Paz-Bailey G, Fischer M (2019) Epidemiology of dengue, chikungunya, and zika virus disease in U.S. States and territories, 2017. Am J Trop Med Hyg 101:884 890. https://doi.org/10.4269/ajtmh.19-0309

Ahmad M, Iram K, Jabeen G (2020a) Perception-based influence factors of intention to adopt COVID-19 epidemic prevention in China. Environ Res 190:109995. https://doi.org/10.1016/j.envres.2020. 109995

Ahmad M, Rehman A, Shah SAA, Solangi YA, Chandio AA, Jabeen G (2020b) Stylized heterogeneous dynamic links among healthcare expenditures, land urbanization, and $\mathrm{CO}_{2}$ emissions across economic development levels. Sci Total Environ 753:142228. https://doi. org/10.1016/j.scitotenv.2020.142228

Ahmad M, Akhtar N, Jabeen G, et al (2021) Intention-based critical factors affecting willingness to adopt novel coronavirus prevention in Pakistan: implications for future pandemics. Int J Environemntal Res Public Heal 18(11):6167. https://doi.org/10.3390/ ijerph18116167

Ali H, Yilmaz G, Fareed Z, Shahzad F, Ahmad M (2020) Impact of novel coronavirus (COVID-19) on daily routines and air environment: evidence from Turkey. Air Qual Atmos Health 14:1-7. https://doi. org/10.1007/s11869-020-00943-2

Anser MK, Yousaf Z, Khan MA, Nassani AA, Abro MMQ, Vo XH, Zaman K (2020) Social and administrative issues related to the COVID-19 pandemic in Pakistan: better late than never. Environ Sci Pollut Res 27:34567-34573. https://doi.org/10.1007/s11356020-10008-7

Araújo MB, Naimi B (2020) Spread of SARS-CoV-2 coronavirus likely constrained by climate. medRxiv:1-26. https://doi.org/10.1101/ 2020.03.12.20034728

Bashir MF, Ma B, Bilal et al (2020) Correlation between climate indicators and COVID-19 pandemic in New York, USA. Sci Total Environ 728:138835. https://doi.org/10.1016/j.scitotenv.2020. 138835

Bhadra A, Mukherjee A, Sarkar K (2020) Impact of population density on Covid-19 infected and mortality rate in India. Model Earth Syst Environ 7:623-629. https://doi.org/10.1007/s40808-020-00984-7

Bu J, Peng DD, Xiao H et al (2020) Analysis of meteorological conditions and prediction of epidemic trend of 2019-nCoV infection in 2020. medRxiv. https://doi.org/10.1101/2020.02.13.20022715

Chen B, Liang H, Yuan X et al (2020a) Roles of meteorological conditions in COVID-19 transmission on a worldwide scale. medRxiv 11. https://doi.org/10.1101/2020.03.16.20037168

Chen S, Prettner K, Cao B, Geldsetzer P, Kuhn M, Bloom DE, Bärnighausen T, Wang C (2020b) Revisiting the association between temperature and COVID-19 transmissibility across 117 countries. Eur J Open Res 6:00550-02020. https://doi.org/10.1183/ 23120541.00550-2020

Chughtai AA, Khan W (2020) Use of personal protective equipment to protect against respiratory infections in Pakistan: a systematic review. J Infect Public Health 13:385-390. https://doi.org/10.1016/j. jiph.2020.02.032

Cissoko M, Sagara I, Sankaré MH, Dieng S, Guindo A, Doumbia Z, Allasseini B, Traore D, Fomba S, Bendiane MK, Landier J, Dessay N, Gaudart J (2020) Geo-epidemiology of malaria at the health area level, dire health district, Mali, 2013-2017. Int J Environ Res Public Health 17:1-16. https://doi.org/10.3390/ ijerph17113982

Coșkun H, Yıldırım N, Gündüz S (2021) The spread of COVID-19 virus through population density and wind in Turkey cities. Sci Total Environ 751:141663. https://doi.org/10.1016/j.scitotenv.2020. 141663

Countrymeters (2021) Pakistan population. https://countrymeters.info/en/ Pakistan

Couto M, Kurowski M, Moreira A, Bullens DMA, Carlsen KH, Delgado L, Kowalski ML, Seys SF (2018) Mechanisms of exercise-induced bronchoconstriction in athletes: current perspectives and future challenges. Allergy Eur J Allergy Clin Immunol 73:8-16. https://doi. org/10.1111/all.13224

Dadbakhsh M, Khanjani N, Bahrampour A, Haghighi PS (2017) Death from respiratory diseases and temperature in Shiraz, Iran (20062011). Int J Biometeorol 61:239-246 https://doi.org/10.1007/ s00484-016-1206-z

Dalziel BD, Kissler S, Gog JR, Viboud C, Bjørnstad ON, Metcalf CJE, Grenfell BT (2018) Urbanization and humidity shape the intensity of influenza epidemics in U.S. cities. Science (80- ) 362:75-79. 362: 75-79. https://doi.org/10.1126/science.aat6030

Diba S, Xie N (2019) Sustainable supplier selection for Satrec Vitalait Milk Company in Senegal using the novel grey relational analysis method. Grey Syst Theory Appl 9:262-294. https://doi.org/10. 1108/gs-01-2019-0003

Elavarasan RM, Pugazhendhi R, Shafiullah GM, Irfan M, AnvariMoghaddam A (2021) A hover view over effectual approaches on pandemic management for sustainable cities - the endowment of prospective technologies with revitalization strategies. Sustain Cities Soc 68:102789. https://doi.org/10.1016/j.scs.2021.102789 
El-Sayed A, Aleya L, Kamel M (2021) COVID-19: a new emerging respiratory disease from the neurological perspective. Environ Sci Pollut Res Int:1-15. https://doi.org/10.1007/s11356-021-12969-9

Fu S, Wang B, Zhou J, Xu X, Liu J, Ma Y, Li L, He X, Li S, Niu J, Luo B, Zhang K (2021) Meteorological factors, governmental responses and COVID-19: evidence from four European countries. Environ Res 194:110596. https://doi.org/10.1016/j.envres.2020.110596

Ghalhari FG, Mayvaneh F (2016) Effect of air temperature and universal thermal climate index on respiratory diseases mortality in Mashhad, Iran. Arch Iran Med 19:618-624

GOP (2021) Coronavirus in Pakistan confirmed cases (GOP). http:// covid.gov.pk/. Accessed 5 Jun 2021

Hansel NN, McCormack MC, Kim V (2016) The effects of air pollution and temperature on COPD. COPD J Chronic Obstr Pulm Dis 13: 372-379. https://doi.org/10.3109/15412555.2015.1089846

Hasana S, Hossain MF, Jalouli M, Kabir MT, Uddin MG, Wahed MII, Behl T, Bin-Jumah MN, Abdel-Daim MM, Aleya L, Uddin MS (2021) Genetic diversity of SARS-CoV2 and environmental settings: possible association with neurological disorders. Mol Neurobiol 58:1917-1931. https://doi.org/10.1007/s12035-02002239-z

Hausman BL, Lawrence HY, Marmagas SW, Fortenberry L, Dannenberg CJ (2020) H1N1 vaccination and health beliefs in a rural community in the Southeastern United States: lessons learned. Crit Public Health 30:245-251. https://doi.org/10.1080/09581596.2018. 1546825

Hossain MF, Hasana S, Mamun AA et al (2020) COVID-19 outbreak: pathogenesis, current therapies, and potentials for future management. Front Pharmacol 11. https://doi.org/10.3389/fphar.2020. 563478

Hussain A, Oad A, Ahmad M, Irfan M (2021) Do financial development and economic openness matter for economic progress in an emerging country? Seeking a sustainable development path. J Risk Financ Manag 14:237. https://doi.org/10.3390/jrfm14060237

Ikram M, Sroufe R, Rehman E, Shah SZA, Mahmoudi A (2020a) Do quality, environmental, and social (QES) certifications improve international trade? A comparative grey relation analysis of developing vs. developed countries. Phys A Stat Mech Its Appl 545:123486. https://doi.org/10.1016/j.physa.2019.123486

Ikram M, Zhang Q, Sroufe R, Shah SZA (2020b) Towards a sustainable environment: the nexus between ISO 14001, renewable energy consumption, access to electricity, agriculture and $\mathrm{CO}_{2}$ emissions in SAARC countries. Sustain Prod Consum 22:218-230. https://doi. org/10.1016/j.spc.2020.03.011

Ikram M, Srouf R, Zhang Q, Ferasso M (2021) Assessment and prediction of environmental sustainability: novel grey models comparative analysis of China vs. the USA. Environ Sci Pollut Res 28:1789117912. https://doi.org/10.1007/s11356-020-11418-3

Iqbal N, Fareed Z, Shahzad F, He X, Shahzad U, Lina M (2020) The nexus between COVID-19, temperature and exchange rate in Wuhan city: new findings from partial and multiple wavelet coherence. Sci Total Environ 729:138916. https://doi.org/10.1016/j. scitotenv.2020.138916

Iqbal S, Bilal AR, Nurunnabi M, Iqbal W, Alfakhri Y, Iqbal N (2021a) It is time to control the worst: testing COVID-19 outbreak, energy consumption and $\mathrm{CO}_{2}$ emission. Environ Sci Pollut Res 28: 19008-19020. https://doi.org/10.1007/s11356-020-11462-z

Iqbal W, Ming Y, Yin K, Irfan M (2021b) Nexus between air pollution and NCOV-2019 in China: application of negative binomial regression analysis. Process Saf Environ Prot 150:557-565. https://doi. org/10.1016/j.psep.2021.04.039

Irfan M, Zhao Z-Y, Ahmad M, Mukeshimana M (2019a) Solar energy development in Pakistan: barriers and policy recommendations. Sustainability 11:1206. https://doi.org/10.3390/su11041206

Irfan M, Zhao ZY, Ahmad M, Rehman A (2019b) A techno-economic analysis of off-grid solar PV system: a case study for Punjab
Province in Pakistan. Processes 7:1-14. https://doi.org/10.3390/ pr7100708

Irfan M, Hao Y, Panjwani MK, Khan D, Chandio AA, Li H (2020a) Competitive assessment of South Asia's wind power industry: SWOT analysis and value chain combined model. Energy Strateg Rev 32:32. https://doi.org/10.1016/j.esr.2020.100540

Irfan M, Zhao ZY, Panjwani MK, Mangi FH, Li H, Jan A, Ahmad M, Rehman A (2020b) Assessing the energy dynamics of Pakistan: prospects of biomass energy. Energy Rep 6:80-93. https://doi.org/ 10.1016/j.egyr.2019.11.161

Irfan M, Zhao ZY, Rehman A, Ozturk I, Li H (2020c) Consumers' intention-based influence factors of renewable energy adoption in Pakistan: a structural equation modeling approach. Environ Sci Pollut Res 28:432-445. https://doi.org/10.1007/s11356-02010504-w

Irfan M, Ahmad M, Fareed Z, Iqbal N, Sharif A, Wu H (2021a) On the indirect environmental outcomes of COVID-19: short-term revival with futuristic long-term implications. Int J Environ Health Res:111. https://doi.org/10.1080/09603123.2021.1874888

Irfan M, Akhtar N, Ahmad M, Shahzad F, Elavarasan RM, Wu H, Yang $\mathrm{C}$ (2021b) Assessing public willingness to wear face masks during the COVID-19 pandemic: fresh insights from the theory of planned behavior. Int J Environ Res Public Health 18:4577. https://doi.org/ 10.3390/ijerph18094577

Irfan M, Elavarasan RM, Hao Y, Feng M, Sailan D (2021c) An assessment of consumers' willingness to utilize solar energy in china: endusers' perspective. J Clean Prod 292:126008. https://doi.org/10. 1016/j.jclepro.2021.126008

Jahangiri M, Jahangiri M, Najafgholipour M (2020) The sensitivity and specificity analyses of ambient temperature and population size on the transmission rate of the novel coronavirus (COVID-19) in different provinces of Iran. Sci Total Environ 728:138872. https://doi. org/10.1016/j.scitotenv.2020.138872

Javed SA, Liu S (2018a) Evaluation of outpatient satisfaction and service quality of Pakistani healthcare projects. Grey Syst Theory Appl 8: 462-480. https://doi.org/10.1108/gs-04-2018-0018

Javed SA, Liu S (2018b) Predicting the research output/growth of selected countries: application of Even GM $(1,1)$ and NDGM models. Scientometrics 115:395-413. https://doi.org/10.1007/s11192-0172586-5

Javed SA, Liu S (2019) Bidirectional absolute GRA/GIA model for uncertain systems: application in project management. IEEE Access 7: 60885-60896. https://doi.org/10.1109/ACCESS.2019.2904632

Javed SA, Zhu B, Liu S (2020) Forecast of biofuel production and consumption in top $\mathrm{CO}_{2}$ emitting countries using a novel grey model. J Clean Prod 276:123997. https://doi.org/10.1016/j.jclepro.2020. 123997

Kaur I, Behl T, Aleya L, Rahman H, Kumar A, Arora S, Bulbul IJ (2021) Artificial intelligence as a fundamental tool in management of infectious diseases and its current implementation in COVID-19 pandemic. Environ Sci Pollut Res Int:1-18. https://doi.org/10.1007/ s11356-021-13823-8

Khan I, Hou F, Irfan M, Zakari A, le HP (2021) Does energy trilemma a driver of economic growth? The roles of energy use, population growth, and financial development. Renew Sust Energ Rev 146: 111157. https://doi.org/10.1016/j.rser.2021.111157

Knüppel M (2014) Efficient estimation of forecast uncertainty based on recent forecast errors. Int J Forecast 30:257-267. https://doi.org/10. 1016/j.ijforecast.2013.08.004

Kumar R, Sharma A, Srivastava JK, Siddiqui MH, Uddin MS, Aleya L (2021) Hydroxychloroquine in COVID-19: therapeutic promises, current status, and environmental implications. Environ Sci Pollut Res:1-14. https://doi.org/10.1007/s11356-020-12200-1

Lalmuanawma S, Hussain J, Chhakchhuak L (2020) Applications of machine learning and artificial intelligence for Covid-19 (SARS- 
CoV-2) pandemic: a review. Chaos, Solitons Fractals 139:110059. https://doi.org/10.1016/j.chaos.2020.110059

Li M, Zhou M, Yang J, Yin P, Wang B, Liu Q (2019) Temperature, temperature extremes, and cause-specific respiratory mortality in China: a multi-city time series analysis. Air Qual Atmos Health 12:539-548. https://doi.org/10.1007/s11869-019-00670-3

Little RJ, Rubin DB (2019) Statistical analysis with missing data. John Wiley \& Sons

Liu S, Wang J, Shen B, Zhai J, Hao H, Zhao L (2017a) Poly(vinylidene fluoride) nanocomposites with a small loading of core-shell structured $\mathrm{BaTiO}_{3} @ \mathrm{Al}_{2} \mathrm{O}_{3}$ nanofibers exhibiting high discharged energy density and efficiency. J Alloys Compd 696:136-142. https://doi. org/10.1016/j.jallcom.2016.11.186

Liu S, Yang Y, Forrest J (2017b) Grey data analysis. Springer, Singapore

Liu J, Zhou J, Yao J, Zhang X, Li L, Xu X, He X, Wang B, Fu S, Niu T, Yan J, Shi Y, Ren X, Niu J, Zhu W, Li S, Luo B, Zhang K (2020) Impact of meteorological factors on the COVID-19 transmission: a multi-city study in China. Sci Total Environ 726:138513. https://doi. org/10.1016/j.scitotenv.2020.138513

Luo B, Liu J, Fei G, Han T, Zhang K, Wang L, Shi H, Zhang L, Ruan Y, Niu J (2017) Impact of probable interaction of low temperature and ambient fine particulate matter on the function of rats alveolar macrophages. Environ Toxicol Pharmacol 49:172-178. https://doi.org/ 10.1016/j.etap.2016.12.011

Ma Y, Zhao Y, Liu J, He X, Wang B, Fu S, Yan J, Niu J, Zhou J, Luo B (2020) Effects of temperature variation and humidity on the death of COVID-19 in Wuhan, China. Sci Total Environ 724:138226. https://doi.org/10.1016/j.scitotenv.2020.138226

MacIntyre CR, Chughtai AA (2020) A rapid systematic review of the efficacy of face masks and respirators against coronaviruses and other respiratory transmissible viruses for the community, healthcare workers and sick patients. Int J Nurs Stud 108:103629. https://doi. org/10.1016/j.ijnurstu.2020.103629

Mahmoudi A, Javed SA, Liu S, Deng X (2020) Distinguishing coefficient driven sensitivity analysis of GRA model for intelligent decisions: application in project management. Technol Econ Dev Econ 26: 621-641. https://doi.org/10.3846/tede.2019.11890

Matterne U, Egger N, Tempes J, et al (2020) Health literacy in the general population in the context of epidemic or pandemic coronavirus outbreak situations: rapid scoping review. Patient Educ Couns

Mazzeu JHG, Ruiz E, Veiga H (2018) Uncertainty and density forecasts of Arma models: comparison of asymptotic, Bayesian, and bootstrap procedures. J Econ Surv 32:388-419. https://doi.org/10.1111/joes. 12197

Mosnier E, Epelboin L, Guiraud N, Huber F, Adriouch L, Guarmit B, Brousse P, Terraz A, Boser A, Gaillet M, Djossou F, Adenis A, Nacher M (2019) Spatial dynamics and epidemiology for AIDS in remote areas in French Guiana. AIDS Care - Psychol Socio-Medical Asp AIDS/HIV 31:498-504. https://doi.org/10.1080/09540121. 2018.1524111

NASA (2021) https://power.larc.nasa.gov/data-access-viewer/. Accessed 5 Jun 2021

Park JE, Son WS, Ryu Y, Choi SB, Kwon O, Ahn I (2020) Effects of temperature, humidity, and diurnal temperature range on influenza incidence in a temperate region. Influenza Other Respir Viruses 14: 11-18. https://doi.org/10.1111/irv.12682

Paull SH, Horton DE, Ashfaq M, Rastogi D, Kramer LD, Diffenbaugh NS, Kilpatrick AM (2017) Drought and immunity determine the intensity of West Nile virus epidemics and climate change impacts. Proc R Soc B Biol Sci 284:20162078. https://doi.org/10.1098/rspb. 2016.2078

Pramanik M, Udmale P, Bisht P, Chowdhury K, Szabo S, Pal I (2020) Climatic factors influence the spread of COVID-19 in Russia. Int J Environ Health Res:1-15. https://doi.org/10.1080/09603123.2020. 1793921

Prasad D (2015) Operation research. Alpha Science, London
Prata DN, Rodrigues W, Bermejo PH (2020) Temperature significantly changes COVID-19 transmission in (sub) tropical cities of Brazil. Sci Total Environ 729:138862. https://doi.org/10.1016/j.scitotenv. 2020.138862

Preti E, Di Mattei V, Perego G et al (2020) The psychological impact of epidemic and pandemic outbreaks on healthcare workers: rapid review of the evidence. Curr Psychiatry Rep 22:43. https://doi.org/10. 1007/s11920-020-01166-z

Qi H, Xiao S, Shi R, Ward MP, Chen Y, Tu W, Su Q, Wang W, Wang X, Zhang Z (2020) COVID-19 transmission in Mainland China is associated with temperature and humidity: a time-series analysis. Sci Total Environ 728:138778. https://doi.org/10.1016/j.scitotenv.2020. 138778

Ran J, Zhao S, Han L, Liao G, Wang K, Wang MH, He D (2020) A reanalysis in exploring the association between temperature and COVID-19 transmissibility: an ecological study with 154 Chinese cities. Eur Respir J 56:2001253. https://doi.org/10.1183/13993003. 01253-2020

Raza A, Khan MTI, Ali Q, Hussain T, Narjis S (2020) Association between meteorological indicators and COVID-19 pandemic in Pakistan. Environ Sci Pollut Res:1-16. https://doi.org/10.1007/ s11356-020-11203-2

Razzaq A, Sharif A, Aziz N, Irfan M, Jermsittiparsert K (2020) Asymmetric link between environmental pollution and COVID-19 in the top ten affected states of US: a novel estimations from quantile-on-quantile approach. Environ Res 191:110189. https:// doi.org/10.1016/j.envres.2020.110189

Rehman E, Ikram M, Feng MT, Rehman S (2020) Sectoral-based $\mathrm{CO}_{2}$ emissions of Pakistan: a novel grey relation analysis (GRA) approach. Environ Sci Pollut Res 27:29118-29129. https://doi.org/ 10.1007/s11356-020-09237-7

Rehman E, Ikram M, Rehman S, Feng MT (2021) Growing green? Sectoral-based prediction of GHG emission in Pakistan: a novel NDGM and doubling time model approach. Environ Dev Sustain 1-23. https://doi.org/10.1007/s10668-020-01163-5

Saha S, Samanta GP (2019) Modelling and optimal control of HIV/AIDS prevention through PrEP and limited treatment. Phys A Stat Mech its Appl 516:280-307. https://doi.org/10.1016/j.physa.2018.10.033

Şahin M (2020) Impact of weather on COVID-19 pandemic in Turkey. Sci Total Environ 728:138810. https://doi.org/10.1016/j.scitotenv. 2020.138810

Sajadi MM, Sajadi MM, Habibzadeh P et al (2020) Temperature, humidity, and latitude analysis to estimate potential spread and seasonality of coronavirus disease 2019 (COVID-19). JAMA Netw Open 3: e2011834-e2011834. https://doi.org/10.1001/jamanetworkopen. 2020.11834

Sarikaya M, Güllü A (2015) Multi-response optimization of minimum quantity lubrication parameters using Taguchi-based grey relational analysis in turning of difficult-to-cut alloy Haynes 25. J Clean Prod 91:347-357. https://doi.org/10.1016/j.jclepro.2014.12.020

Shahzad F, Shahzad U, Fareed Z, Iqbal N, Hashmi SH, Ahmad F (2020a) Asymmetric nexus between temperature and COVID-19 in the top ten affected provinces of China: a current application of quantile-onquantile approach. Sci Total Environ 736:139115. https://doi.org/ 10.1016/j.scitotenv.2020.139115

Shahzad K, Shahzad U, Iqbal N, Shahzad F, Fareed Z (2020b) Effects of climatological parameters on the outbreak spread of COVID-19 in highly affected regions of Spain. Environ Sci Pollut Res 27:3965739666. https://doi.org/10.1007/s11356-020-10551-3

Sharafkhani R, Khanjani N, Bakhtiari B, Jahani Y, Tabrizi JS, Tabrizi FM (2019) Diurnal temperature range and mortality in Tabriz (the northwest of Iran). Urban Clim 27:204-211. https://doi.org/10.1016/j. uclim.2018.11.004

Sherin A (2020) Coronavirus disease 2019 (Covid-19): a challenge of protecting the general population and health-care workers. Khyber 
Med Univ J 12:2019-2020. https://doi.org/10.35845/kmuj.2020. 20224

Shi P, Dong Y, Yan H, Zhao C, Li X, Liu W, He M, Tang S, Xi S (2020) Impact of temperature on the dynamics of the COVID-19 outbreak in China. Sci Total Environ 728:138890. https://doi.org/10.1016/j. scitotenv.2020.138890

Shim E, Tariq A, Choi W, Lee Y, Chowell G (2020) Transmission potential and severity of COVID-19 in South Korea. Int J Infect Dis 93: 339-344. https://doi.org/10.1016/j.ijid.2020.03.031

Tan J, Mu L, Huang J, Yu S, Chen B, Yin J (2005) An initial investigation of the association between the SARS outbreak and weather: with the view of the environmental temperature and its variation. J Epidemiol Community Health 59:186-192. https://doi.org/10.1136/jech.2004. 020180

Tian H, Li Y, Liu Y et al (2020) Early evaluation of the Wuhan City travel restrictions in response to the 2019 novel coronavirus outbreak. medRxiv. https://doi.org/10.1101/2020.01.30.20019844

Tosepu R, Gunawan J, Savitri D et al (2020) Correlation between weather and Covid-19 pandemic in Jakarta, Indonesia. Sci Total Environ 725:138436. https://doi.org/10.1016/j.scitotenv.2020.138436

Vairo F, Haider N, Kock R, Ntoumi F, Ippolito G, Zumla A (2019) Chikungunya: epidemiology, pathogenesis, clinical features, management, and prevention. Infect Dis Clin N Am 33:1003-1025. https://doi.org/10.1016/j.idc.2019.08.006

Wang D (2017) Impact of SA8000 on China's export enterprises based on the demand curve gray correlation method and the countermeasures. J Discret Math Sci Cryptogr 20:849-860. https://doi.org/10. 1080/09720529.2017.1358866

Wang Q, Zhao Y, Zhang Y, Qiu J, Li J, Yan N, Li N, Zhang J, Tian D, Sha X, Jing J, Yang C, Wang K, Xu R, Zhang Y, Yang H, Zhao S,
Zhao Y (2021) Could the ambient higher temperature decrease the transmissibility of COVID-19 in China? Environ Res 193:110576. https://doi.org/10.1016/j.envres.2020.110576

Waris A, Atta UK, Ali M, Asmat A, Baset A (2020) COVID-19 outbreak: current scenario of Pakistan. New Microbes New Infect 35:100681. https://doi.org/10.1016/j.nmni.2020.100681

Wenjun C, Ziwei F, Guoqiang H et al (2020) The psychological impact of the COVID-19 epidemic on college students in China. Psychiatry Res 287:1-5. https://doi.org/10.1016/j.psychres.2020.112934

Worldometers (2020) https://www.worldometers.info/coronavirus/ countries-where-coronavirus-has-spread/. Accessed 5 Jun 2021

Yasir A, Hu X, Ahmad M, Rauf A, Shi J, Ali Nasir S (2020) Modeling impact of word of mouth and E-Government on online social presence during COVID-19 outbreak: a multi-mediation approach. Int J Environ Res Public Health 17:2954. https://doi.org/10.3390/ ijerph17082954

Yin H, Sun T, Yao L, Jiao Y, Ma L, Lin L, Graff JC, Aleya L, Postlethwaite A, Gu W, Chen H (2021) Association between population density and infection rate suggests the importance of social distancing and travel restriction in reducing the COVID-19 pandemic. Environ Sci Pollut Res:1-7. https://doi.org/10.1007/s11356-02112364-4

Zhicai Z, Li C (2018) Analysis on decision-making model of plan evaluation based on grey relation projection and combination weight algorithm. J Syst Eng Electron 29:789-796. https://doi.org/10. 21629/JSEE.2018.04.13

Publisher's note Springer Nature remains neutral with regard to jurisdictional claims in published maps and institutional affiliations. 